\title{
OPEN Publisher Correction: On the role of ocular torsion in binocular visual matching
}

\section{Bernhard J. M. Hess}

Correction to: Scientific Reports https://doi.org/10.1038/s41598-018-28513-8, published online 13 July 2018

This Article contains typographical errors in the Discussion section where,

"This surface of binocular corresponding points in the visual field is a quadratic surface, as already assumed by Helmholtz ${ }^{17}$ hundred and fifty years ago (Fig. 8)."

should read:

"This surface of binocular corresponding points in the visual field is a quadratic surface, as already assumed by Helmholtz ${ }^{23}$ hundred and fifty years ago (Fig. 8)."

Additionally,

"The iso-torsion contours on this surface (sketched for $\pm 1^{\circ}$ and $\pm 2^{\circ}$ torsion for each eye) cannot be obtained by intersecting it with a plane, a technique that Helmholtz used to determine his twisted cubic horopter curve $e^{17}$, because these curves have fractional exponents."

should read:

"The iso-torsion contours on this surface (sketched for $\pm 1^{\circ}$ and $\pm 2^{\circ}$ torsion for each eye) cannot be obtained by intersecting it with a plane, a technique that Helmholtz used to determine his twisted cubic horopter curve $e^{23}$, because these curves have fractional exponents."

In addition, this Article contains an error in Equation $1 \mathrm{~b}$.

$$
\hat{g}_{b}=R_{F} \hat{d}_{b} R_{F}^{-1}=Q_{b} \hat{e}_{1}+\left\{S_{b} \cos \xi_{b}+R_{b} \sin \xi_{b}\right\} \hat{e}_{2}-\left\{R_{b} \cos \xi_{a}-S_{b} \sin \xi_{b}\right\} \hat{e}_{3}
$$

should read:

$$
\hat{g}_{b}=R_{F} \hat{d}_{b} R_{F}^{-1}=Q_{b} \hat{e}_{1}+\left\{S_{b} \cos \xi_{b}+R_{b} \sin \xi_{b}\right\} \hat{e}_{2}-\left\{R_{b} \cos \xi_{b}-S_{b} \sin \xi_{b}\right\} \hat{e}_{3}
$$


(c) (i) Open Access This article is licensed under a Creative Commons Attribution 4.0 International License, which permits use, sharing, adaptation, distribution and reproduction in any medium or format, as long as you give appropriate credit to the original author(s) and the source, provide a link to the Creative Commons license, and indicate if changes were made. The images or other third party material in this article are included in the article's Creative Commons license, unless indicated otherwise in a credit line to the material. If material is not included in the article's Creative Commons license and your intended use is not permitted by statutory regulation or exceeds the permitted use, you will need to obtain permission directly from the copyright holder. To view a copy of this license, visit http://creativecommons.org/licenses/by/4.0/.

(c) The Author(s) 2019 